\title{
Evaluation of curcumin efficacy against rotenone toxicity in rat model of Parkinson's disease
}

\author{
Ahmed M. Salem ${ }^{1}$, Karima A. El-Shamy ${ }^{2}$, Emad K. Ahmed ${ }^{1 *}$, Yasser A. Khadrawy ${ }^{2}$, Nevein N. \\ Fadl $^{2}$ and Eman N. Hosny ${ }^{2}$ \\ ${ }^{1}$ Biochemistry Department, Faculty of Science, Ain Shams University, Cairo, Egypt \\ ${ }^{2}$ Medical Physiology Department, Medical Division, National Research Centre, Giza, Egypt
}

\section{A RTICLE INFO}

Article history:

Received 21 March 2016

Accepted 18 April 2016

Keywords:

Parkinson's disease;

Rotenone;

Curcumin;

Oxidative stress;

Neuroinflammation;

Locomotor activity.

\begin{abstract}
A B S T R A C T
Curcumin is a phenolic compound and a major component of the dietary spice turmeric (Curcuma longa). The present study aims to investigate the efficacy of curcumin against rotenone toxicity in a rat model of Parkinson's disease (PD). Rats were divided into four groups: control, PD model induced via i.p. injection of rotenone $(1.5 \mathrm{mg} / \mathrm{kg})$, orally protected group received curcumin $(80 \mathrm{mg} / \mathrm{kg})$ before rotenone injection and orally treated group received curcumin $(80 \mathrm{mg} / \mathrm{kg})$ after PD model induction. The data revealed a decrease in motor activity and monoamine content in the midbrain and striatum of PD rat model. This was accompanied with a state of oxidative and nitrosative stress in both areas as indicated from the increased levels of lipid peroxidation and nitric oxide together with the decreased level of reduced glutathione as well as glutathione-Stransferase and superoxide dismutase activities. Also, rotenone decreased acetylcholinesterase and $\mathrm{Na}^{+} / \mathrm{K}^{+}$-ATPase activities and increased tumor necrosis factor- $\alpha$ (TNF- $\alpha$ ) level in both brain areas. Protection and treatment with curcumin prevented the decline induced by rotenone in motor activity and muscular strength and induced a parallel restoration in midbrain and striatal dopamine levels. This was associated with an improvement in norepinephrine and serotonin levels in the two regions. Moreover, curcumin protection and treatment ameliorated most of the changes in oxidative stress parameters induced by rotenone and improved the histopathological alterations in the two brain areas. The present study showed that curcumin offered significant neuroprotective and therapeutic effects against the neurochemical, histopathological and behavioral changes in rotenone-induced rat model of PD.
\end{abstract}

\section{Introduction}

Parkinson's disease (PD) is a chronically progressive neurodegenerative disease that usually presents between the fifth and seventh decade. It is characterized pathologically by a progressive degeneration of dopaminergic neurons projecting from the substantia nigra pars compacta (SNpc) to striatum resulting, primarily, in motor clinical symptoms which include resting tremor on one (or both) sides of the body, bradykinesia, rigidity, and abnormal postural reflexes ${ }^{[1]}$. The chronic and progressive SNpc neuronal cell loss results in striatal dopamine (DA) depletion, and consequently in the movement difficulties displayed during the disease. The symptoms arise when approxi-

\footnotetext{
* Corresponding author.

E-mail address: emad.ahmed@sci.asu.edu.eg
}

mately $60 \%$ of the neurons are lost, which results in about $80 \%$ DA depletion in the striatum ${ }^{[2]}$. The presence of intracellular inclusions called Lewy bodies in the surviving DA neurons of the substantia nigra (SN) has been considered the histopathological hallmark of PD. Lewy bodies are composed of aggregates of $\alpha$-synuclein protein ${ }^{[3]}$.

Brain of rat can be divided anatomically into three main parts; forebrain, midbrain and hindbrain. Forebrain includes cerebral cortex, hippocampus, striatum, thalamus and hypothalamus. The midbrain includes superior, inferior colliculus and midbrain. Finally, the hindbrain includes the cerebellum, pons and medulla ${ }^{[4]}$. The genetic Mendelian forms of PD are rare and $\sim 95 \%$ of cases are sporadic and in these, the exact cause is incompletely understood, but the disorder is largely 
believed to result from exposure to an environmental toxins and a genetic susceptibility ${ }^{[5]}$. In this context, evidence from epidemiological studies implicates a number of insecticides and pesticides in increasing the risk of PD development ${ }^{[6]}$. One such toxin, "rotenone", a pesticide and a mitochondrial complex-I inhibitor has been shown to replicate many features of PD including nigrostriatal cell loss and Lewy body like inclusions when injected into rodents ${ }^{[7]}$.

Despite massive progress in the treatment of $\mathrm{PD}$, there is no exact cure for PD. In clinical practice, levodopa is the most potent drug for controlling motor symptoms of PD. Catechol-O-methyltransferase (COMT) inhibitors, DA agonists and anticholinergics are alternative modalities in the management of PD and may be used concomitantly with levodopa or one another ${ }^{[8]}$. However, many undesirable side effects have been reported due to the use of these medications. Levodopa loses its effectiveness after prolonged use and induces severe side effects like dyskinesia, nausea, and induction of hallucinations and confusion ${ }^{[9]}$. Some side effects have been associated with COMT inhibitors such as diarrhea and increase in liver enzymes ${ }^{[10]}$. Similarly, many side effects have been reported with the use of DA agonists including nausea, vomiting, orthostatic hypotension [11], hallucinations, and delusions ${ }^{[12]}$. Moreover, the usefulness of anticholinergics is limited by the anticholinergic side effects such as cognitive impairment, dry mouth and urinary symptoms ${ }^{[8]}$. Consequently, there is a pressing need to find safer and more effective antiparkinsonian agents. The use of medicinal herbs may provide a better alternative to the frequently used drugs to lessen the side effects and improve the efficacy.

The polyphenol curcumin is a yellow pigment and the main active component derived from the rhizome of the plant Curcuma longa ${ }^{[\mathbf{1 3 , 1 4}]}$. Curcumin was first isolated from turmeric in 1815, and the structure was delineated as diferuloylmethane in $1910^{[13]}$. Curcumin has been widely used as an antiseptic, analgesic, antimalarial, insect repellant, and anti-protozoal, anti-bacterial, immunomodulatory, neuroprotective and cancer chemopreventive agent for hundreds of years ${ }^{[13]}$. Curcumin has been shown to exhibit antioxidant and anti-inflammatory activities [13,14] providing neuroprotective activity against various neurologic diseases, including Alzheimer's disease ${ }^{[15]}$, multiple sclerosis ${ }^{[16]}$ and cerebral ischemia ${ }^{[17]}$.

Although several approved drugs may alleviate PD symptoms, the occurrence of severe drug-induced side effects restricted their usage, and none of these drugs can slow down, prevent or reverse the progress of PD. The development of safe and effective antiparkensonian agents is a persistent need to overcome the reported side effects of the well established drugs. Therefore our study aims to investigate the effect of curcumin on the behavioral, neurochemical and histopathological changes generated in rat model of PD induced by rotenone.

\section{Materials and Methods \\ Animals}

Male Wistar albino rats weighing 150-175g obtained from the Animal House Colony of the National Research Centre, Giza, Egypt were used in the present study. The animals were housed in stainless steel cages with $\mathrm{ad}$ libitum access to standard laboratory diet and tap water in a temperature-controlled $\left(20-25^{\circ} \mathrm{C}\right)$ and artificially illuminated (12 hs dark/light cycle) room free of any chemical contamination. The study was approved by the institutional ethics committee of the Animals Care and Use Committee of National Research Centre, Egypt, on July 2009 with registration number 09/093.

\section{Chemicals}

Rotenone was purchased from Sigma Chemical Co. (St. Louis MO, USA). The chemical was dissolved in dimethylsulfoxide $(1.5 \mathrm{mg} / 50 \mu \mathrm{l})$ and then diluted with sunflower oil to reach a final concentration of $1.5 \mathrm{mg} / \mathrm{ml}$. Curcumin was purchased from Alpha Chemika (Mombai, India). Curcumin was dissolved in dimethylsulfoxide $(1 \mathrm{~g} / 1.25 \mathrm{ml})$ then completed with sunflower oil to have a final concentration of $40 \mathrm{mg} / \mathrm{ml}$.

\section{Experimental Model}

Animals were assigned randomly into four groups (10 rats each). Control group received sunflower vehicle (1 $\mathrm{ml} / \mathrm{kg}$ ) daily through intraperitoneal injection (i.p.). Rotenone-induced PD model group (RmPD) was induced by the daily i.p. injection of rotenone (1.5 $\mathrm{mg} / \mathrm{kg}$ ) for 45 days according to Sun et al. ${ }^{[18]}$. Curcumin protected group (CUR/Pr) received curcumin orally through stomach tube $(80 \mathrm{mg} / \mathrm{kg})^{[19]}$ followed by the daily i.p. injection of rotenone with one hour interval for 45 days. Curcumin treated group (CUR/Tr) administered with curcumin $(80 \mathrm{mg} / \mathrm{kg})$ daily for 45 days after the establishment of PD model.

\section{Behavioral analysis}

At the end of the experiment, rats were screened for motor impairments using the open-field test, the traction test and the forelimb hanging test.

Open field $(\mathrm{OF})$ test

The apparatus was a square $72 \times 72 \mathrm{~cm}$ with surrounding walls of $30 \mathrm{~cm}$ height. The base of the OF was divided into 36 squares. The central zone represented $25 \%$ of the total arena. The duration of the test was set to be ten minutes for each rat. The OF parameters measured were the number of squares crossed, the time spent in the central zone, the number of rears and the freezing time [20]

\section{Forelimb hanging test}

The wire hanging test was performed using a modified method of Fan et al. [21]. This maneuver tests neuromuscular and locomotor development ${ }^{[22]}$. Each rat was suspended grasping by its forelimb into a wire (20 mm thick) $50 \mathrm{~cm}$ above a foam cushion and the time to drop was recorded. This procedure was repeated 3 times for each rat and then the mean was calculated for each rat. A longer time was taken as an indicator of better strength or motor endurance. 
The traction test

The traction test was carried out as described by Dai et al. ${ }^{[23]}$. The rats were suspended by their front paws to a wire placed horizontally. Scoring was as follows; 3: the rat grasps the wire with two hind paws. 2: the rat grasps the wire with one hind paw. 1: the rat cannot grasp the wire with neither hind paws.

\section{Preparation of samples}

Following behavioral testing, animals were sacrificed by sudden decapitation. The brain of each animal was quickly removed and rapidly transferred to an ice-cold Petri dish. Each brain was divided into two halves; right and left. Each half was dissected to obtain the midbrain and the striatum. Each brain area was weighed and frozen at $-80^{\circ} \mathrm{C}$ until analyzed. The right half of each midbrain and striatum was homogenized in Tris- $\mathrm{HCl}$ buffer ( $\mathrm{pH}$ 7.4) and used for the determination of oxidative stress parameters, enzyme activities and TNF$\alpha$. The left half of each area was homogenized in an icecold solution of acidified $n$-butanol and used for monoamines analysis.

\section{Neurochemical analysis}

\section{Determination of monoamines concentrations}

The quantitative determination of dopamine (DA), norepinephrine (NE) and serotonin (5-HT) levels was carried out according to the method of Ciarlone ${ }^{[24]}$ using a spectrofluorometer (Jasco FP-6500, with a source of xenon arc lamp 150 watt, JASCO Ltd., Tokyo, Japan).

Determination of acetylcholinesterase activity

The procedure used for the determination of acetylcholinesterase (AchE) activity in the midbrain and striatum was a modification of the method of Ellman et al. ${ }^{[25]}$ as described by Gorun et al. ${ }^{[26]}$. The principle of the method is the measurement of the thiocholine produced as acetylthiocholine is hydrolyzed. The color was read immediately at $412 \mathrm{~nm}$. The results were expressed as $\mu \mathrm{mol} \mathrm{SH} / \mathrm{min} / \mathrm{g}$ brain tissue.

\section{Determination of lipid peroxidation}

Lipid peroxidation was assayed by measuring the levels of malondialdehyde (MDA) in the brain tissues. MDA was determined by measuring thiobarbituric reactive species using the method of Ruiz-Larrea et al. ${ }^{\text {[27] }}$ in which the thiobarbituric acid reactive substances react with thiobarbituric acid to produce a pink colored complex whose absorbance is read at $532 \mathrm{~nm}$.

Determination of nitric oxide

Nitric oxide (NO) was determined spectrophotometrically in the brain tissue according to the method described by Montgomery and Dymock ${ }^{[28]}$. This method depends on the measurement of endogenous nitrite concentration as an indicator of nitric oxide production. The resulting azo dye has a bright reddish-purple color whose absorbance is read at $540 \mathrm{~nm}$.

\section{Determination of reduced glutathione}

The assay of reduced glutathione (GSH) levels was performed according to the spectrophotometric method of Beutler et al. ${ }^{[29]}$. It depends on the reduction of 5,5'dithiobis-2-nitrobenzoic acid (DTNB) with glutathione to produce a yellow color, the absorbance of which is measured at $405 \mathrm{~nm}$.

Determination of glutathione-S-transferase activity

Glutathione-S-transferase (GST) activity was determined according to the method of Habig et al. ${ }^{[30]}$. $0.4 \mathrm{ml}$ potassium phosphate buffer $(50 \mathrm{mmol} / \mathrm{l} ; \mathrm{pH} 6.5), 0.1 \mathrm{ml}$ of supernatant, $1.2 \mathrm{ml}$ water and $0.1 \mathrm{ml} \mathrm{1-chloro-2,4-}$ dinitrobenzene $(30 \mathrm{mmol} / \mathrm{l})$ were added and incubated in a water bath at $37^{\circ} \mathrm{C}$ for $10 \mathrm{~min}$. After incubation, $0.1 \mathrm{ml}$ of reduced glutathione $(30 \mathrm{mmol} / \mathrm{l})$ was added. The change in absorbance was measured at $340 \mathrm{~nm}$ at one min interval. The results were expressed as units/g brain tissue, where one unit of enzyme is defined as the amount of enzyme that conjugates 1 mmole of CDNB with GSH per minute.

Determination of superoxide dismutase activity

Superoxide dismutase (SOD) was determined using Biodiagnostic Kit No. SD 2521 (Biodiagnostic Co., Egypt) based on the method of Nishikimi et al. ${ }^{[31]}$. This method relies on the ability of the enzyme to inhibit the phenazine methosulphate-mediated reduction of nitroblue tetrazolium dye. The change in absorbance over $5 \mathrm{~min}$ after addition of phenazine methosulphate is read at $560 \mathrm{~nm}$. The results were expressed as units/g brain tissue, where 1.5 U/assay of the purified SOD enzyme produced $80 \%$ inhibition of phenazine methosulphate-mediated reduction of nitroblue tetrazolium dye.

\section{Determination of $\mathrm{Na}^{+} / \mathrm{K}^{+}$- ATPase activity}

$\mathrm{Na}^{+} / \mathrm{K}^{+}$-ATPase activity was measured spectrophotometrically according to Bowler and Terii ${ }^{[32]}$ as described by Tsakiris et al. ${ }^{[33]}$. $\mathrm{Na}^{+} / \mathrm{K}^{+}$-ATPase activity was calculated as the difference between total ATPase activity $\left(\mathrm{Na}^{+} / \mathrm{K}^{+}\right.$-ATPase and $\mathrm{Mg}$-ATPase activity) and Mg-ATPase activity. The results were expressed as $\mu \mathrm{mol} \mathrm{Pi} / \mathrm{min} / \mathrm{g}$ brain tissue.

\section{Determination of tumor necrosis factor-alpha}

Tumor necrosis factor-alpha (TNF- $\alpha$ ) was measured using rat TNF- $\alpha$ ELISA kit obtained from Koma Biotech Inc.(Yeongdeungpo-gu, Seoul 150-105, Korea). The developed color was read at $450 \mathrm{~nm}$ using a microtiter plate reader. The concentration was then calculated from a standard curve.

\section{Histopathological Examination}

For histopathological assessment by light microscopy, the brains of two rats from each group were gently excised, washed with normal saline, fixed in $10 \%$ buffered neutral formalin, embedded in paraffin and cut serially at $5 \mu \mathrm{m}$ thickness. Routine staining of sections with hematoxylin-eosin (H\&E) was performed ${ }^{[34]}$.

\section{Statistical analysis}

All results were expressed as means \pm S.E.M. Statistical difference between the groups under investigation was tested by one-way analysis of variance (ANOVA) followed by post hoc test using Duncan. The open field test data were analyzed with the non-parametric Kruskal Wallis one-way ANOVA test followed by the Mann Whitney paired comparison. Difference was considered significant at $p$-value $\leq 0.05$. Statistical Package for 
Social Sciences (SPSS) software (version 16) was used for all statistical calculations.

\section{Results}

\section{Behavioral data}

\section{Open field test (OFT)}

The present findings showed significant differences in OFT parameters among control rats, rat model of PD (RmPD) and rat model of PD protected (CUR/Pr) and treated (CUR/Tr) with curcumin (Table 1).

A significant increase in the central square duration $(+320.42 \%)$ and freezing time (+503.53\%) together with a significant decrease in the number of crossed squares $(-83.51 \%)$ and number of rears $(-85.51 \%)$ were recorded in rotenone-induced $\mathrm{PD}$ rats $(\mathrm{RmPD})$ compared to control group. Curcumin protection (CUR/Pr) and treatment (CUR/Tr) ameliorated the changes induced by rotenone to nearly control values except for the length of freezing time which recorded a sharp significant decrease $(-85.60 \%)$ in PD rats treated with curcumin (CUR/Tr) compared to controls.

Forelimb hanging and traction tests

In PD animals (RmPD) the forelimb hanging time and the traction test were recording a significant decrease of $-68.71 \%$ and $-62.89 \%$, respectively, below the control values. Protection and treatment of parkinsonian rats with curcumin prevented the sharp decrease in the values of these two parameters with respect to control (Table 1).

\section{Neurochemical data}

Monoamine Neurotransmitters

As shown in Table (2), statistical analysis revealed a significant decrease in the levels of midbrain and striatal DA $(-37.36 \%$ and $-49.23 \%$, respectively), NE $(-52.94 \%$ and $-51.85 \%$, respectively) and $5-\mathrm{HT}(-47.62 \%$ and
$-46.43 \%$, respectively) in parkinsonian rats (RmPD) below the control value. The protection of parkinsonian rats with curcumin (CUR/Pr) prevented the recorded decrease in the three midbrain and striatal monoamine levels. When the animal model of PD was treated daily with curcumin (CUR/Tr), the decrease in the midbrain and striatal DA was restored to control like value. Curcumin treatment also restored the midbrain NE level but failed to restore striatal $\mathrm{NE}$ and midbrain 5-HT. However, curcumin treatment reversed the decreased striatal 5-HT induced by rotenone into a significant increase.

\section{Acetylcholinesterase}

In the midbrain and striatum of rat model of PD (RmPD), AchE activity showed a significant decrease recording $-22.60 \%$ and $-38.02 \%$, respectively as compared to control values. Protection of parkinsonian rats with curcumin (CUR/Pr) caused AchE activity to be increased significantly in the midbrain $(+15.57 \%)$ and striatum $(+56.10 \%)$. Also, curcumin treatment (CUR/Tr) restored the decrease in the midbrain AchE activity induced by rotenone and significantly increased striatal AchE activity (+56.64\%) as compared to control group (Table 3).

\section{$\mathrm{Na}^{+} / \mathrm{K}^{+}$-ATPase}

$\mathrm{Na}^{+} / \mathrm{K}^{+}$-ATPase activity decreased significantly in the midbrain and striatum of parkinsonian rats (RmPD) recording $(-21.54 \%$ and $-28.21 \%$, respectively) below control values. In the striatum, curcumin protection (CUR/Pr) restored the $\mathrm{Na}^{+} / \mathrm{K}^{+}$-ATPase activity to control values; however it failed to recover the enzyme activity in the midbrain. On the other hand, curcumin treatment (CUR/Tr) didn't correct the inhibition in the midbrain and striatal $\mathrm{Na}^{+} / \mathrm{K}^{+}$-ATPase activity induced by rotenone (Table 3).

Table 1: Effect of curcumin protection and therapy on open field test parameters, forelimb hanging and traction tests in rat model of PD.

\begin{tabular}{|c|c|c|c|c|c|c|}
\hline & \multicolumn{4}{|c|}{ Open field test } & \multirow{2}{*}{$\begin{array}{c}\begin{array}{c}\text { Forelimb } \\
\text { hanging test }\end{array} \\
\text { Time } \\
\text { (sec.) }\end{array}$} & \multirow{2}{*}{$\begin{array}{c}\text { Traction test } \\
\text { Score }\end{array}$} \\
\hline & $\begin{array}{l}\text { No. of squares } \\
\text { crossed }\end{array}$ & $\begin{array}{l}\text { Central square } \\
\text { duration } \\
\text { (sec.) }\end{array}$ & No. of rears & $\begin{array}{l}\text { Freezing time } \\
\quad(\mathrm{sec} .)\end{array}$ & & \\
\hline Control & $50.02^{\mathrm{a}} \pm 10.33$ & $2.40^{\mathrm{a}} \pm 0.32$ & $16.08^{\mathrm{a}} \pm 3.98$ & $3.68^{\mathrm{a}} \pm 1.02$ & $15.31^{\mathrm{a}} \pm 0.27$ & $2.91^{\mathrm{a}} \pm 0.09$ \\
\hline RmPD & $8.25^{\mathrm{b}} \pm 2.50$ & $10.09^{b} \pm 3.16$ & $2.33^{\mathrm{b}} \pm 0.93$ & $22.21^{\mathrm{b}} \pm 0.53$ & $4.79^{b} \pm 0.15$ & $1.08^{b} \pm 0.08$ \\
\hline CUR/Pr & $50.11^{\mathrm{a}} \pm 7.07$ & $2.55^{\mathrm{a}} \pm 0.28$ & $14.86^{\mathrm{a}} \pm 3.07$ & $6.31^{\mathrm{a}} \pm 1.62$ & $16.25^{\mathrm{a}} \pm 0.48$ & $2.83^{a} \pm 0.11$ \\
\hline CUR/Tr & $51.00^{\mathrm{a}} \pm 7.22$ & $2.53^{\mathrm{a}} \pm 0.23$ & $13.80^{\mathrm{a}} \pm 5.13$ & $0.53^{\mathrm{c}} \pm 0.21$ & $16.35^{\mathrm{a}} \pm 0.44$ & $2.83^{\mathrm{a}} \pm 0.11$ \\
\hline
\end{tabular}

RmPD: Rotenone-induced PD model group; CUR/Pr: rat model of PD protected with curcumin; CUR/Tr: rat model of PD treated daily with curcumin.

Results are expressed as mean \pm S.E.M for 10 animals / group.

Statistically significant means $(p$-value $\leq 0.05)$ are given in different letters. 
Table 2: Effect of curcumin protection and therapy on monoamines levels in the midbrain and striatum of rat model of PD.

\begin{tabular}{ccccccc}
\hline & \multicolumn{3}{c}{ Midbrain } & \multicolumn{2}{c}{ Striatum } \\
& DA & NE & $5-\mathrm{HT}$ & DA & NE & $5-\mathrm{HT}$ \\
Control & $0.91^{\mathrm{a}} \pm 0.02$ & $0.34^{\mathrm{a}} \pm 0.01$ & $0.42^{\mathrm{a}} \pm 0.01$ & $0.65^{\mathrm{a}} \pm 0.01$ & $0.27^{\mathrm{a}} \pm 0.01$ & $0.28^{\mathrm{a}} \pm 0.01$ \\
RmPD & $0.57^{\mathrm{b}} \pm 0.01$ & $0.16^{\mathrm{b}} \pm 0.002$ & $0.22^{\mathrm{b}} \pm 0.003$ & $0.33^{\mathrm{b}} \pm 0.01$ & $0.13^{\mathrm{b}} \pm 0.004$ & $0.15^{\mathrm{b}} \pm 0.004$ \\
CUR/Pr & $0.96^{\mathrm{a}} \pm 0.01$ & $0.35^{\mathrm{a}} \pm 0.01$ & $0.43^{\mathrm{a}} \pm 0.01$ & $0.63^{\mathrm{a}} \pm 0.01$ & $0.27^{\mathrm{a}} \pm 0.01$ & $0.28^{\mathrm{a}} \pm 0.01$ \\
CUR/Tr & $0.88^{\mathrm{a}} \pm 0.02$ & $0.32^{\mathrm{a}} \pm 0.01$ & $0.22^{\mathrm{b}} \pm 0.001$ & $0.60^{\mathrm{a}} \pm 0.01$ & $0.19^{\mathrm{c}} \pm 0.004$ & $0.40^{\mathrm{c}} \pm 0.01$ \\
\hline
\end{tabular}

RmPD: Rotenone-induced PD model group; CUR/Pr: rat model of PD protected with curcumin; CUR/Tr: rat model of PD treated daily with curcumin.

Results are expressed as mean \pm S.E.M for 8 animals / group.

Statistically significant means $(p$-value $\leq 0.05)$ are given in different letters.

Table 3: Effect of curcumin protection and therapy on the activities of AchE and $\mathrm{Na}^{+} / \mathrm{K}^{+}$-ATPase in the midbrain and striatum of rat model of PD.

\begin{tabular}{|c|c|c|c|c|}
\hline & \multicolumn{2}{|c|}{ Midbrain } & \multicolumn{2}{|c|}{ Striatum } \\
\hline & $\begin{array}{c}\text { AchE } \\
(\mu \mathrm{mol} \mathrm{SH} / \mathrm{g} / \mathrm{min})\end{array}$ & $\begin{array}{l}\mathrm{Na}^{+}, \mathrm{K}^{+}-\mathrm{ATPase} \\
(\mu \mathrm{mol} \mathrm{Pi} / \mathrm{min} / \mathrm{g})\end{array}$ & $\begin{array}{c}\text { AchE } \\
(\mu \mathrm{mol} \mathrm{SH} / \mathrm{g} / \mathrm{min})\end{array}$ & $\begin{array}{l}\mathrm{Na}^{+} / \mathrm{K}^{+}-\mathrm{ATPase} \\
(\mu \mathrm{mol} \mathrm{Pi} / \mathrm{min} / \mathrm{g})\end{array}$ \\
\hline Control & $34.16^{\mathrm{a}} \pm 1.16$ & $0.65^{\mathrm{a}} \pm 0.01$ & $44.65^{\mathrm{a}} \pm 0.94$ & $0.39^{\mathrm{a}} \pm 0.01$ \\
\hline RmPD & $26.44^{b} \pm 0.88$ & $0.51^{b} \pm 0.01$ & $27.67^{b} \pm 0.88$ & $0.28^{b} \pm 0.01$ \\
\hline CUR/Pr & $39.48^{c} \pm 0.73$ & $0.52^{b} \pm 0.02$ & $69.70^{c} \pm 2.19$ & $0.41^{\mathrm{a}} \pm 0.01$ \\
\hline CUR/Tr & $34.52^{\mathrm{a}} \pm 1.03$ & $0.51^{\mathrm{b}} \pm 0.01$ & $69.94^{c} \pm 1.62$ & $0.32^{\mathrm{c}} \pm 0.01$ \\
\hline
\end{tabular}

RmPD: Rotenone-induced PD model group, CUR/Pr: rat model of PD protected with curcumin, CUR/Tr: rat model of PD treated daily with curcumin.

Results are expressed as mean \pm S.E.M for 8 animals / group.

Statistically significant means ( $p$-value $\leq 0.05$ ) are given in different letters.

\section{Oxidative stress parameters}

As shown in Figure (1) animals of the PD model group (RmPD) demonstrated a significant increase in the midbrain and striatal MDA $(+29.12 \%$ and $+50.62 \%$, respectively) and NO $(+93.97 \%$ and $+28.65 \%$, respectively) levels above the control values. However, a significant decrease in GSH level $(-48.80 \%$ and $-46.55 \%)$, GST activity $(-20.86 \%$ and $-29.64 \%)$, and SOD activity $(-27.38 \%$ and $-35.41 \%)$ was recorded in the midbrain and striatum, respectively, in the parkinsonian rats (RmPD). Curcumin protection (CUR/Pr) prevented the increase in MDA level and the decrease in GST and SOD activities and significantly increased GSH level $(+34.94 \%)$ in the midbrain. Treatment of parkinsonian rats with curcumin (CUR/Tr) resulted in a significant decrease in MDA (-13.49\%) and a significant increase in GSH $(+73.49 \%)$ and restored NO level, GST and SOD activities. In the striatum, curcumin protection (CUR/Pr) reversed the increase in MDA level into a significant decrease $(-27.27 \%)$ and the significant decrease in SOD activity into a significant increase $(+19.72 \%)$ and restored levels of NO, GSH and GST activity to control values. Curcumin treatment (CUR/Tr) also restored NO, MDA and SOD activity and significantly increased GSH level $(+55.17 \%)$. However, curcumin treatment failed to restore the decrease in GST activity induced by rotenone.

Tumor necrosis factor-alpha

Figure (1) shows that the daily i.p. injection of rotenone for 45 days (RmPD) induced a significant increase in TNF- $\alpha$ levels in the midbrain and striatum recording $+18.95 \%$ and $+28.93 \%$, respectively, as compared with the control group. However, both the protection (CUR/Pr) and treatment (CUR/Tr) of PD rats with curcumin normalized the significant increase induced by rotenone injection in midbrain and striatal TNF- $\alpha$ levels.

\section{Histopathological investigations}

In the midbrain of control rats, large nerve cells which were mostly multipolar, stellate or pyriform and astrocytes appeared with sharply demarcated nuclei and 

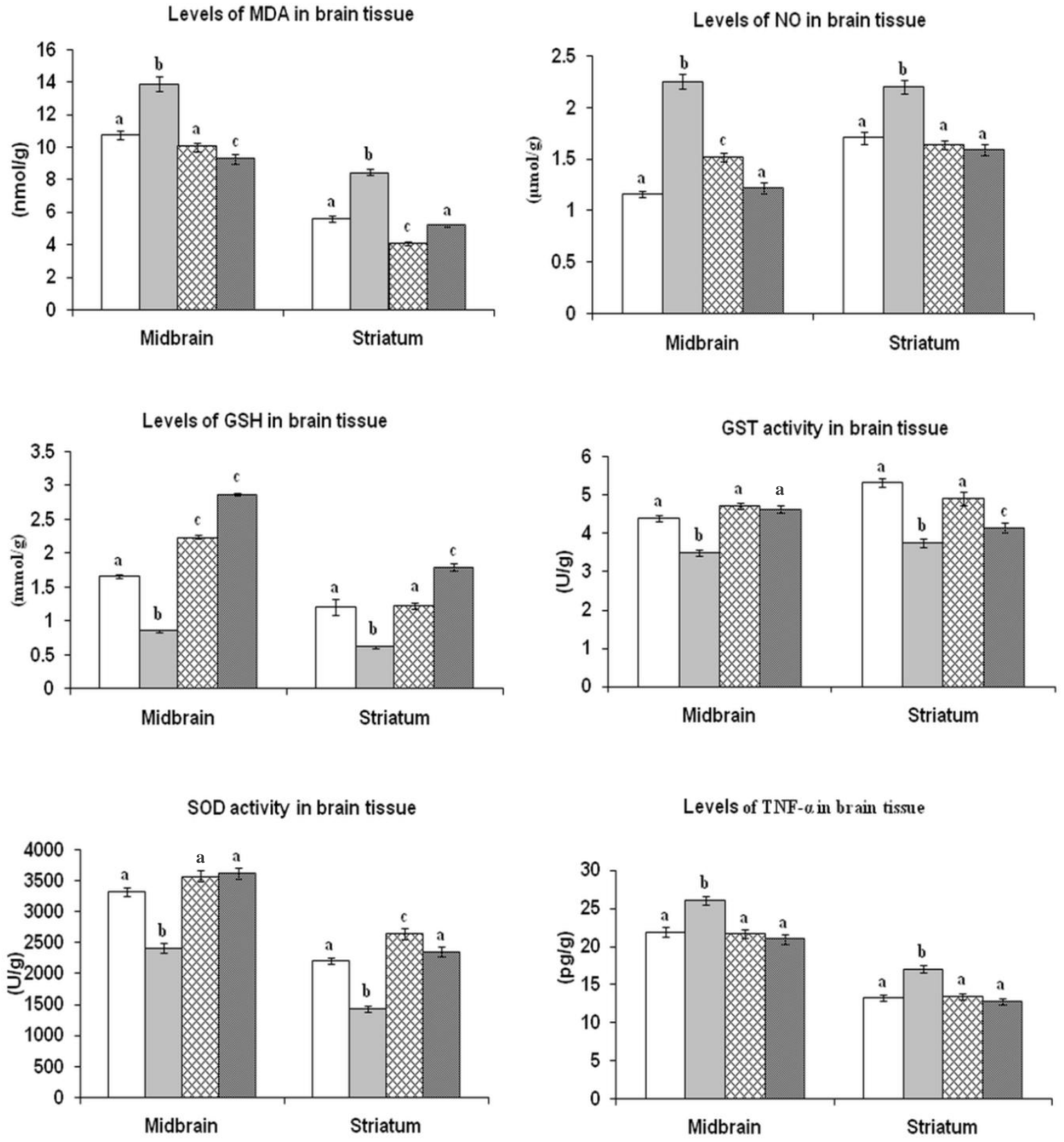

Figure (1): Effect of curcumin on oxidative stress parameters and level of TNF- $\alpha$ in the midbrain and striatum of rat model of PD.
$\square$ Control
ХCUR/Pr; curcumin protected group
RmPD: Rotenone-induced PD model group
眮 CUR/Tr; curcumin treated group
Statistically significant means $(p$-value $\leq 0.05)$ are given in different letters.

normal structure (Figure 2-A). The histopathological examination of the midbrain of PD-induced rat model showed prominent degeneration of the neurons, apoptosis and presence of cytoplasmic inclusions of Lewy bodies. In addition, there was evidence of pyknotic nuclei, chromatin condensation and perineuronal vacuolation (Figure 2-B). The protection and treatment of rat model of PD with curcumin improved the histopathological changes induced in the midbrain (Figure 2-C and 2-D). This effect was more prominent in case of curcumin protection.

Histological examination of the striatum from control group revealed normal neuronal structure. Neurons retained their shape and normal cellular configuration with obvious nuclei was clear (Figure 3-A). However, in the striatum of rat model of PD, severe focal encephalomalacia, neuronal degeneration and gliosis were observed (Figure 3-B). These histopathological changes were reduced in the striatum when the parkinsonian rats were protected or treated with curcumin (Figures 3-C, 3-D).

\section{Discussion}

The main hallmark of PD is the depletion of DA content in the basal ganglia with the appearance of Lewy bodies. This decrease in DA content in the basal ganglia leads to the motor deficits that characterize the PD. 


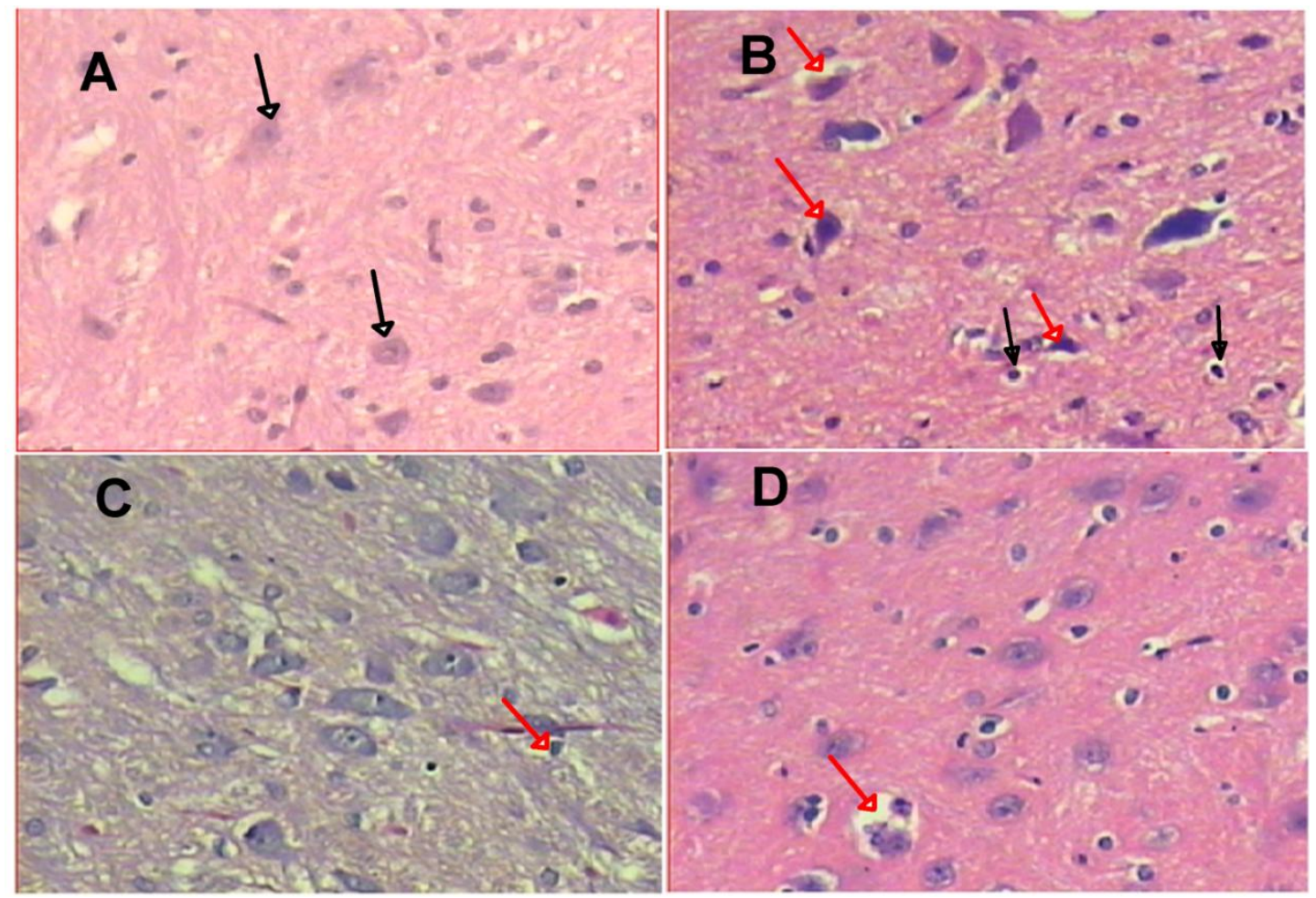

Figure (2): Histopathological section of midbrains of $(\mathrm{H} \& \mathrm{E} \times 400)$; (A) control rat showing normal neurons (black arrow), (B) rat model of PD showing prominent degeneration of the neurons (red arrows) and presence of cytoplasmic inclusions of Lewy bodies (black arrow), (C) rat model of PD protected with curcumin which appear more or less like the control with few neurodegenerations (red arrow), (D) rat model of PD treated with curcumin showing neurodegenerations of the neurons (red arrow).

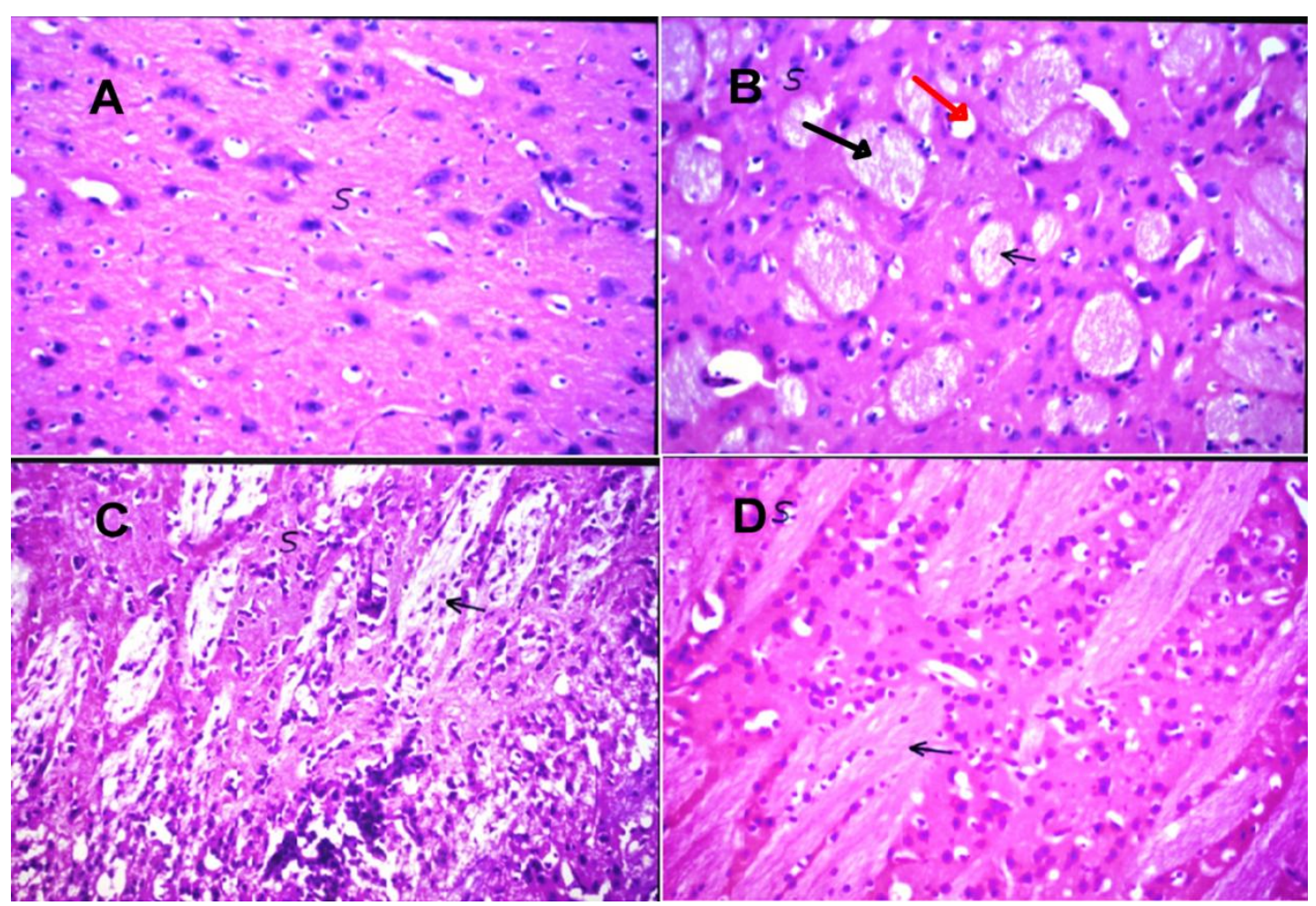

Figure (3): Histopathological section of striatums of $(\mathrm{H} \& \mathrm{E} \times 400)$; (A) control rat showing normal neurons, (B) rat model of PD showing multiple focal encephalomalacia (black arrow), gliosis (g) and neurodegenerations (red arrow), (C) rat model of PD protected with curcumin appear more or less like the control with few focal encephalomalacia and gliosis (black arrow), (D) rat model of PD treated with curcumin showing few focal encephalomalacia and gliosis (black arrow). 
In the present study, the rat model of PD showed a significant disturbance in motor activity. This was indicated from the significant decrease in the number of crossed lines and number of rearings together with the significant increase in the central duration and freezing times. In addition, there was a significant decrease in the time of the forelimb hanging test and the score of the traction test which were used to assess motor neuron function and the performance of the skeletal muscles. These behavioral symptoms were associated with a significant decrease in DA levels in the striatum and midbrain of rat model of PD induced by rotenone and the neuronal degeneration as well as Lewy bodies that have been shown in the histolopathological examination of the two studied brain regions.

It has been reported that rotenone is one of the potent dopaminergic neurotoxicants. It can easily cross the blood-brain barrier and accumulate in the mitochondria, where it binds specifically to complex I, disrupting mitochondrial respiration and increasing reactive oxygen species (ROS) production [35]. Mitochondrial dysfunction in turn causes N-methyl-D-aspartate (NMDA) receptor activation, which leads to further mitochondrial impairment ${ }^{[36]}$. The hyperexcitability mediated by massive stimulation of NMDA results in a massive influx of calcium ions $\left(\mathrm{Ca}^{2+}\right)$ and the formation of ROS and reactive nitrogen species (RNS), which in turn cause lipid peroxidation, and mitochondrial and nuclear DNA damage ${ }^{[37]}$. This could explain the state of oxidative stress that has been observed in the striatum and midbrain due to rotenone administration. In addition, the present increase in NO levels could be attributed to rotenone-induced activation of NO synthase reported by $\mathrm{He}$ et al. ${ }^{[38]}$. NO in turn could react with ROS, especially superoxide to form peroxynitrite, a potent oxidant and nitrating agent which has the ability to modify proteins, lipids, and nucleic acids ${ }^{[39]}$. The present increase in the lipid peroxidation confirms the development of the state of oxidative stress in the striatum and midbrain of PD rat model. The decrease in GSH level and the activities of SOD and GST could be due to their consumption in overcoming the increased ROS and RNS generated under the effect of rotenone.

In the present study, an increase in TNF- $\alpha$ was observed in the striatum and midbrain of the PD model. This cytokine could have a crucial role in the dopaminergic degeneration induced by rotenone. TNF- $\alpha$ plays a promoting role in neuroinflammation-mediated progressive degeneration of dopaminergic neurons in $\mathrm{PD}{ }^{[40]}$. It may thus damage the dopaminergic neurons and consequently lead to the decrease in DA content in the striatum and midbrain and consequently the motor deficits that have been observed in the present model of PD. The decrease in $\mathrm{Na}^{+} / \mathrm{K}^{+}$-ATPase activity that has been observed in the PD rats may indicate the damaging effect of rotenone on the cell membrane. $\mathrm{Na}^{+} / \mathrm{K}^{+}$ATPase is an embedded pump in the cell membrane which plays a role in the maintenance of neuronal excitability through the generation of the membrane potential by the active transport of sodium $\left(\mathrm{Na}^{+}\right)$and potassium $\left(\mathrm{K}^{+}\right)$ions in the CNS ${ }^{[\mathbf{4 1 , 4 2}]}$.

The decrease in DA content in the striatum will lead to an increase in acetylcholine (Ach) release. This is due to the inhibitory effect of DA on Ach release ${ }^{[43]}$. Therefore, the striatal DA/Ach balance will be deteriorated leading to cholinergic hyperactivity which mediates the tremor, rigidity, muscle fatigue and postural instability ${ }^{[43]}$. Accordingly, the present significant decrease in AchE activity, the Ach-metabolizing enzyme, may arise from its consumption to meet the hypercholinergic activity.

In the present study, the significant decrease in NE and 5-HT in the midbrain and striatum of rat model of PD could mediate many of the non-motor symptoms that appear in parkinsonian patients such as depression and mood disturbance ${ }^{[44]}$. The present decrease in NE and 5HT could be attributed to the stimulatory effect of rotenone on monoamine oxidase (MAO), the monoamine metabolizing enzyme ${ }^{[45]}$.

In the present study, both protection and treatment with curcumin improved the motor dysfunction induced by rotenone. This effect could be due to curcumin-induced restoration of DA level in the two studied brain regions. The present recovery in midbrain and striatal DA may be attributed to the reported inhibitory effect of curcumin on MAO ${ }^{[46,47]}$ preventing the breakdown of DA and increasing its level in the striatum and midbrain.

Curcumin is highly lipophilic, it can easily cross the blood-brain barrier and reach the brain ${ }^{[48]}$, where it has beneficial antioxidant effects ${ }^{[14]}$. The free radical scavenging ability of curcumin may be attributed to its classical structure containing phenolic and methoxy group on the phenyl ring and 1,3-diketone ${ }^{[49]}$ rendering it capable of preventing lipid oxidation. Moreover, curcumin can lower lipid peroxidation in mouse brain by maintaining the activities of antioxidant enzymes like SOD and catalase at higher levels ${ }^{[50]}$.

On the other hand, the present recovery of midbrain and striatal NO after curcumin treatment may be attributed to the NO scavenging activity of curcumin ${ }^{[51]}$ or the curcumin-mediated suppression of inducible nitric oxide synthase expression ${ }^{[52]}$, thus reducing the production of NO. Moreover, it has been found that curcumin protected neurons from glutamate insult by reducing $\mathrm{Ca}^{2+}$ influx ${ }^{[53]}$ where $\mathrm{Ca}^{2+}$ influx stimulates neuronal nitric oxide synthase ${ }^{[54]}$. Therefore, the inhibition of $\mathrm{Ca}^{2+}$ influx by curcumin represents one of the mechanisms by which curcumin prevents the oxidative and nitrosative stress induced by rotenone in the midbrain and striatum and consequently ameliorates the neuronal damage.

In the present study, the increase in GSH due to curcumin protection and treatment could be attributed to the reported curcumin-induced glutamylcysteine ligase gene expression (the rate-limiting enzyme in GSH biosynthesis), which increases glutamylcysteine ligase activity ${ }^{[55]}$ thereby increasing total cellular GSH levels. It has also been demonstrated that curcumin increased the activity of GST enzyme ${ }^{[56]}$. Therefore, the present recovery of GST activity in the midbrain may be 
attributed to the stimulatory effect of curcumin on GSH synthesis and GST activity besides the direct ROS scavenging activity of curcumin. However, curcumin therapy failed to restore the decrease in GST activity in the striatum. This may be a brain region-specific effect. Certain regions of central nervous system, such as the striatum, are particularly sensitive to oxidative stress because of their low endogenous levels of $\alpha$-tocopherol [57]. The low antioxidant defense capacity can predispose the striatum to oxidative stress. Therefore, the inability of curcumin to activate GST in the striatum could be attributed to the nature of this region as the decrease in GST may be due to its exhaustion to compensate the low antioxidant capacity of the striatum.

In addition to its antioxidant capacity, curcumin exhibited an anti-inflammatory effect, in the present study, as evidenced from its ability to restore the rotenone-induced increase in TNF- $\alpha$. This effect may be mediated by curcumin-induced inhibition of TNF- $\alpha$ gene expression ${ }^{[58]}$ and the inhibition of microglial activation ${ }^{[59]}$

The present findings demonstrated that rotenone induced a state of severe oxidative stress and inflammation which in turn may result in irreversible neuronal cell membrane degeneration and a permanent decrease in $\mathrm{Na}^{+} / \mathrm{K}^{+}$-ATPase activity. Therefore, although curcumin protection and treatment alleviated the oxidative stress and inflammation, it failed to restore the recorded inhibition in $\mathrm{Na}^{+} / \mathrm{K}^{+}$-ATPase activity.

Protection and treatment of parkinsonian rats with curcumin reduced rotenone-induced oxidative stress, excitotoxicity, elevated levels of NO and TNF- $\alpha$. These beneficial effects of curcumin could stop the progression of neurodegeneration induced by rotenone but couldn't restore the histopathological changes. This may be expected since neuronal damage is an irreversible effect and requires prolonged time to be recovered due to the unique nature of neuronal tissues. This could explain why the improvement in histopathological changes was more prominent when curcumin was used as a protective agent.

The present data demonstrated that protection with curcumin against rotenone intoxication significantly increased midbrain and striatal AchE activities which may be a feed-back mechanism by which curcumin normalizes Ach levels. Moreover, the daily treatment of PD rat model with curcumin restored the significant decrease in AchE activity induced by rotenone to control-like value in the midbrain and increased striatal AchE activity significantly. It has been demonstrated that the activity of AchE is inhibited by free radical formation ${ }^{[60]}$ and since curcumin is a potent free radical scavenger besides its ability to reduce oxidative damage by enhancing the antioxidant defense systems of the brain, it may attenuate the significant decrease induced by rotenone in midbrain and striatal AchE activity.
It is clear from the present results that curcumin protection was effective in preventing the depletion of midbrain and striatal NE level induced by rotenone, while the therapeutic effect of curcumin on NE level appeared only in the midbrain. In addition, both curcumin protection and therapy were effective in restoring the decreased level of 5-HT induced by rotenone in the midbrain and striatum to control-like level. Since MAO is the metabolizing enzyme of NE and 5-HT, the inhibitory effect of curcumin on this enzyme activity could mediate the restoration of $\mathrm{NE}$ and 5-HT. This effect may be beneficial in preventing the state of depression and insomnia associated with PD.

The present data showed that protection with curcumin is more efficient than treatment with curcumin against the changes induced in the midbrain and striatum of rat model of PD.

In conclusion, the present study demonstrated that curcumin administration potentially reversed rotenoneinduced alterations in behavioral and neurochemical parameters in rats. These beneficial effects of curcumin may be attributed partially to its antioxidant and antiinflammatory efficacy. Since curcumin is a natural polyphenol without any reported side effects, our findings suggest that curcumin supplementation as a part of our diet might be a useful adjunct in the prevention and treatment of PD.

\section{References}

1) Wooten, G. F. (1997). Neurochemistry and neuropharmacology of Parkinson's disease. In: Watts, R. L. and Koller, W. C. (Eds), Movement disorders: neurologic principles and practice, McGraw-Hill, NY.

2) Schulz, J. B. and Falkenburger, B. H. (2004). Neuronal pathology in Parkinson's disease. Cell Tissue Res., 318: 135-147. Schulz, J. B. and Falkenburger, B. H. (2004). Neuronal pathology in Parkinson's disease. Cell Tissue Res., 318: 135-147.

3) Jomova, K., Vondrakova, D., Lawson, M. and Valko, M. (2010). Metals, oxidative stress and neurodegenerative disorders. Mol. Cell Biochem., 345: 91-104.

4) Zeman, W. and Innes, J. R. M. (1963). Graigie's Neuroanatomy of the Rat. Academic Press, New York, London.

5) Polito, L., Greco, A. and Seripa, D. (2016). Genetic profile, environmental exposure and their interaction in Parkinson's disease. Parkinsons Dis. 2016: 6465793.

6) Hancock, D. B., Martin, E. R., Mayhew, G. M., Stajich, J. M., Jewett, R., Stacy, M. A., Scott, B. L., Vance, J. M. and Scott, W. K. (2008). Pesticide exposure and risk of Parkinson's disease: a familybased case-control study. BMC Neurol., 8:6. doi:10.1186/1471-2377-8-6.

7) Sherer, T. B., Kim, J. H., Betarbet, R. and Greenamyre, J. T. (2003). Subcutaneous rotenone exposure causes highly selective dopaminergic degeneration and alpha-synuclein aggregation. 
Exp. Neurol., 179: 9-16.

8) Jankovic, J. and Aguilar, L. G. (2008). Current approaches to the treatment of Parkinson's disease. Neuropsychiatr. Dis. Treat., 4: 743-757.

9) David, G. S. and Anne, B. Y. (2007). Treatment of central nervous system degenerative disorders. In: Brunton, L. P. (Ed.), The pharmacological basis of therapeutics, 11th Ed., McGraw hill publication, NY.

10) Ruottinen, H. M. and Rinne, U. K. (1998). COMT inhibition in the treatment of Parkinson's disease. J. Neurol., 245: 25-34.

11) Micieli, G., Martignoni, E., Cavallini, A., Pacchetti, C., Rossi, F., Horowski, R. and Nappi, G. (1996). Lisuride and bromocriptine in L-dopa stable-responder parkinsonian patients: a comparative, doubleblind evaluation of cardiopressor and neurochemical effects. Funct. Neurol., 11: 317-325.

12) Nadeau, S. E. (1997). Parkinson's disease. J. Am. Geriatr. Soc., 45: 233-240.

13) Aggarwal, B. B., Sundaram, C., Malani, N. and Ichikawa, H. (2007). Curcumin: the Indian solid gold. Adv. Exp. Med. Biol., 595: 1-75.

14) Hatcher, H., Planalp, R., Cho, J., Torti, F. M. and Torti, S. V. (2008). Curcumin: from ancient medicine to current clinical trials. Cell. Mol. Life Sci., 65: 1631-1652.

15) Ishrat, T., Hoda, M. N., Khan, M. B., Yousuf, S., Ahmad, M., Khan, M. M., Ahmad, A. and Islam, F. (2009). Amelioration of cognitive deficits and neurodegeneration by curcumin in rat model of sporadic dementia of Alzheimer's type (SDAT). Eur. Neuropsychopharmacol., 19: 636-647.

16) Natarajan, C. and Bright, J. J. (2002). Curcumin inhibits experimental allergic encephalomyelitis by blocking IL-12 signaling through Janus kinaseSTAT pathway in T lymphocytes. J. Immunol., 168: 6506-6513.

17) Shukla, P. K., Khanna, V. K., Ali, M. M., Khan, M. Y. and Srimal, R. C. (2007). Anti-ischemic effect of curcumin in rat brain. Neurochem. Res., 33: 1036-1043.

18) Sun, Y., Zhang, G., Xu, J., Chen, S., Tao, E., Xu, C. and Bennett, M. C. (2010). Effect of rifampicin pre- and post-treatment on rotenone induced dopaminergic neuronal apoptosis and alphasynuclein expression. Neural Regen. Res., 5: 85-91.

19) Ishrat, T., Hoda, M. N., Khan, M. B., Yousuf, S., Ahmad, M., Khan, M. M., Ahmad, A. and Islam, F. (2009). Amelioration of cognitive deficits and neurodegeneration by curcumin in rat model of sporadic dementia of Alzheimer's type (SDAT). Eur. Neuropsychopharmacol., 19: 636-647.

20) Brown, R. E., Corey, S. C. and Moore, A. K. (1999). Differences in measures of exploration and fear in MHC-congenic C57BL/6J and B6-H-2K mice. Behavior Genetics, 29: 263-271.

21) Fan, L. W., Chen, R. F., Mitchell, H. J., Lin, R. C. S., Simpson, K. L., Rhodes, P. G. and Cai, Z.
(2008). $\alpha$-Phenyl-n-tert-butylnitrone attenuates lipopolysaccharide-induced brain injury and improves neurological reflexes and early sensorimotor behavioral performance in juvenile rats. J. Neurosci. Res., 86: 3536-3547.

22) Hermans, R. H., Hunter, D. E., McGivern, R. F., Cain, C. D. and Longo, L. D. (1992). Behavioral sequelae in young rats of acute intermittent antenatal hypoxia. Neurotoxicol. Teratol., 14: 119-129.

23) Dai, S. F., Han, G. Z., Li, Y., Yu, D. Q., Zhang, D. M., Feng, Y. H., Zhao, J. and Sun, Y. P. (2008). Effects of nicotine on the microglia of Parkinson's disease mice. Asian J. of Pharmacodynamics and Pharmacokinetics, 8: 319-323.

24) Ciarlone, A. E. (1978). Further modification of a fluoromertric method for analyzing brain amines. Microchem. J., 23: 9-12.

25) Ellman, G. L., Courtney, K. D., Andres, V. and Featherstone, R. M. (1961). A new and rapid colorimetric determination of acetylcholinesterase activity. Biochem. Pharmacol., 7: 88-95.

26) Gorun, V., Proinov, I., Baltescu V., Balaban, G. and Barzu, O. (1978). Modified Ellman procedure for assay of cholinesterase in crude-enzymatic preparations. Anal. Biochem., 86: 324-326.

27) Ruiz-Larrea, M. B., Leal, A. M., Liza, M., Lacort, M. and de Groot, H (1994). Antioxidant effects of estradiol and 2-hydroxyestradiol on iron-induced lipid peroxidation of rat liver microsomes. Steroids, 59: $383-388$.

28) Montgomery, H. A. C. and Dymock, J. F. (1961). The determination of nitrite in water. Analyst, 86: 414-416.

29) Beutler, E., Duron, O. and Kelly, B. M. (1963). Improved method for the determination of blood glutathione. J. Lab Clin. Med., 61: 882-888.

30) Habig, W. H., Pabst, M. J. and Jacoby, W. B. (1973). Glutathione-S-transferase; The first enzymatic step in mercapturic acid formation. J. Biochem., 249: 7130-7139.

31) Nishikimi, M., Appaji, N. and Yogi, K. (1972). The occurrence of superoxide anion in the reaction of reduced phenazine methosulfate and molecular oxygen. Biochem. Biophys. Res. Common., 46: 849854.

32) Bowler, K. and Tirri, R. (1974). The temperature characteristics of synaptic membrane ATPases from immature and adult rat brain. J. Neurochem., 23: 611613.

33) Tsakiris, S., Angelogianni, P., Schulpis, K. H. and Behrakis, P. (2000). Protective effect of 1-cysteine and glutathione on rat brain $\mathrm{Na}^{+}, \mathrm{K}^{+}$ATPase inhibition induced by free radicals. Z Naturforsch., 55: 271-277.

34) Banchroft, J. D., Steven, A. and Turner, D. R. (1996). Theory and practice of histological technique. $4^{\text {th }}$ edn. Churchil Livingstone, New York, London, San Francisco, Tokyo.

35) Betarbet, R., Sherer, T. B., MacKenzie, G., Garcia-Osuna, M., Panov, A. V. and Greenmyre, 
J. T. (2000). Chronic systemic pesticide exposure reproduces features of Parkinson's disease. Nat. Neurobiol., 3: 1301-1306.

36) Greenamyre, J. T., MacKenzie, G., Peng, T. I. and Stephans, S. E. (1999). Mitochondrial dysfunction in Parkinson's disease. Biochem. Soc. Symp., 66: 85-97.

37) Fonnum, F. and Lock, E. A. (2004). The contributions of excitotoxicity, glutathione depletion and DNA repair in chemically induced injury to neurones: exemplified with toxic effects on cerebellar granule cells. J. Neurochem., 88: 513-531.

38) He, Y., Imam, S. Z., Dong, Z., Jankovic, J., Ali, S. F., Appel, S. H. and Le, W. (2003). Role of nitric oxide in rotenone-induced nigro-striatal injury. $\mathrm{J}$. Neurochem., 86: 1338-1345.

39) Korhonen, R., Lahti, A., Kankaanranta, H. and Moilanen, E. (2005). Nitric oxide production and signaling in inflammation. Curr. Drug Targets Inflamm. Allergy., 4: 471-479.

40) Montgomery, S. L. and Bowers, W. J. (2012). Tumor necrosis factor-alpha and the roles it plays in homeostatic and degenerative processes within the central nervous system. J. Neuroimmun. Pharmacol., 7: 42-59.

41) Erecinska, M. and Silver, I. A. (1994). Ions and energy in mammalian brain. Prog. Neurobiol., 16: 37-71.

42) de Lores Arnaiz, G. R. and Ordieres M. G. (2014). Brain $\left.\left.\mathrm{Na}^{+}\right), \mathrm{K}^{+}\right)$-ATPase activity in aging and disease. Int. J. Biomed. Sci., 10: 85-102.

43) Swathi, G., Bhuvaneswar, C. and Rajendra, W. (2013). Alterations of cholinergic neurotransmission in rotenone induced parkinson's disease: protective role of bacopa monnieri. Int. J. Pharm. Biol. Sci., 3: 286-292.

44) Kiss, P. J. (2008). Theory of active antidepressants: a nonsynaptic approach to the treatment of depression. Neurochem. Int., 52: 34-39.

45) Swathi, G. and Rajendra, W. (2014). Protective role of bacopa monnieri on induced Parkinson's disease with particular reference to catecholamine system. Int. J. Pharm. Pharm. Sci., 6: 379-382.

46) Mazzio, E. A., Harris, N. and Soliman, K. F. (1998). Food constituents attenuate oxidase activity and peroxide levels in C6 cells. Planta Med., 64: 603-607.

47) Bhutani, M. K., Bishnoi, M. and Kulkarni, S. K. (2009). Anti-depressant like effect of curcumin and its combination with piperine in unpredictable chronic stress-induced behavioral, biochemical and neurochemical changes. Pharmacol. Biochem. Behav., 92: 39-43.

48) Tsai, Y. M., Chien, C. F., Lin, L. C. and Tsai, T. H. (2011). Curcumin and its nano-formulation: the kinetics of tissue distribution and blood-brain barrier penetration. Int. J. Pharm., 416: 331-338.

49) Priyadarsini, K. I., Maity, D. K., Naik, G. H., Kumar, M. S., Unnikrishnan, M. K., Satav, J. G. and Mohan, H. (2003). Role of phenolic O-H and methylene hydrogen on the free radical reactions and antioxidant activity of curcumin. Free Radic. Biol. Med., 35: 475-484.

50) Rajeswari, A. (2006). Curcumin protects mouse brain from oxidative stress caused by 1-methyl-4phenyl-1,2,3,6-tetrahydropyridine. Eur. Rev. Med. Pharmacol. Sci., 10: 157-161.

51) Sumanont, Y., Murakami, Y., Tohda, M., Vajragupta, O., Watanabe, H. and Matsumoto, K. (2006). Prevention of kainic acid-induced changes in nitric oxide level and neuronal cell damage in the rat hippocampus by manganese complexes of curcumin and diacetylcurcumin. Life Sci., 78: 1884-1891.

52) Begum, A. N., Jones, M. R., Lim, G. P., Morihara, T., Kim, P., Heath, D. D., Rock, C. L., Pruitt, M. A., Yang, F., Hudspeth, B., Hu, S., Faull, K. F., Teter, B., Cole, G. M. and Frautschy, S. A. (2008). Curcumin structure-function, bioavailability, and efficacy in models of neuroinflammation and Alzheimer's disease. J. Pharmacol. Exp. Ther., 326: 196-208.

53) Chen, K., An, Y., Tie, L., Pan, Y. and Li, X. (2015). Curcumin Protects Neurons from GlutamateInduced Excitotoxicity by Membrane Anchored AKAP79-PKA Interaction Network. Evid. Based Complement. Alternat. Med., 2015: 1-9.

54) Bolaños, J. P. and Almeida, A. (1999). Roles of nitric oxide in brain hypoxia-ischemia. Biochim. Biophys. Acta., 1411: 415-436.

55) Dickinson, D. A., Iles, K. E., Zhang, H., Blank, V. and Forman, H. J. (2003). Curcumin alters EpRE and AP-1 binding complexes and elevates glutamatecysteine ligase gene expression. FASEB J., 17: 473475.

56) Iqbal, M., Sharma, S. D., Okazaki, Y., Fujisawa, M. and Okada, S. (2003). Dietary supplementation of curcumin enhances antioxidant and phase II metabolizing enzymes in ddY male mice: possible role in protection against chemical carcinogenesis and toxicity. Pharmacol. Toxicol., 92: 33-38.

57) Gottlieb, M., Leal-Campanario, R., CamposEsparza, M. R., Sánchez-Gómez, M. V., Alberdi, E., Arranz, A., Delgado-García, J. M., Gruart, A. and Matute, C. (2006). Neuroprotection by two polyphenols following excitotoxicity and experimental ischemia. Neurobiol. Dis., 23: 374-386.

58) Zhou, H., Beevers, C. S. and Huang, S. (2011). The targets of curcumin. Curr. Drug Targets, 12: 332-347.

59) Yang, S., Zhang, D., Yang, Z., Hu, X., Qian, S., Liu, J., Wilson, B., Block, M. and Hong, J. S. (2008). Curcumin protects dopaminergic neuron against LPS induced neurotoxicity in primary rat neuron/ glia culture. Neurochem. Res., 33: 20442053.

60) Tsakiris, S., Angelogianni, P., Schulpis, K. H. and Stavridis, C. (2000). Protective effect of Lphenylalanine on rat brain acetylcholineesterase inhibition induced by free radicals. Clin. Biochem., 33: 103-106. 